\title{
Percepção da População do Centro da Cidade de Juazeiro do Norte sobre a Expansão dos Empreendimentos de Origem Asiática
}

\author{
Maria Luana de Melo ${ }^{1}$; Tharsis Cidália de Sá Barreto Diaz Alencar ${ }^{2}$
}

\begin{abstract}
Resumo: Evidencia-se ao longo dos relatos históricos a forte imigração asiática para o Brasil ao longo dos anos, motivados pela oportunidade de trabalho, desenvolvendo principalmente atividades voltadas para agricultura em lavouras de café, como também pela motivação de iniciar uma nova vida. Atualmente ainda é notório o fluxo de imigração, principalmente chinesa, para o nosso país, distribuídos por várias regiões do país. Dado o exposto a pesquisa tem como objetivo compreender como a população do centro da cidade enxerga à expansão de empresas de origem asiática na cidade de Juazeiro do Norte. Identificando o que tem ocasionado tal expansão dessas empresas de acordo com a percepção dos mesmos. A pesquisa em questão é de natureza básica, de abordagem quantitativa e trata-se de uma pesquisa de opinião desenvolvida com a população do centro da cidade de Juazeiro do Norte. De acordo com a percepção dos entrevistados esses empreendimentos de origem asiática estão avançando e crescendo cada vez mais na economia da cidade e isto pode estar diretamente ligado a forma de atuação dessas empresas, ofertando produtos similares aos originais a preços baixos, mas mantendo a qualidade. E tal crescimento pode afetar os empreendimentos locais, que irão sofrer com a forte concorrência desses empreendimentos.
\end{abstract}

Palavras Chave: Imigrantes asiáticos. Expansão de empreendimentos. Cenário econômico

\section{Perception of the Population of the City Center of Juazeiro do Norte on the Expansion of Asian Enterprises}

\begin{abstract}
It is evidenced over the historical accounts the strong Asian immigration to Brazil over the years, motivated by the opportunity to work, developing mainly agricultural activities in coffee plantations, as well as the motivation to start a new life. Currently it is still notorious immigration flow, mainly Chinese, to our country, spread over various regions of the country. Given the above research, aims to understand how the population of the City Centre sees the expansion of Asian origin in the city of Juazeiro do Norte. Identifying what has raised such expansion of these companies according to the perception of them. The research in question is basic in nature, of a quantitative approach and it is a poll developed with the population from the center of the city of Juazeiro do Norte. According to the perception of respondents, these enterprises of Asian origin are advancing and growing increasingly the city's economy and this can be directly linked to the form of performance of these companies, offering similar products at low prices to the originals, but keeping the quality. In addition, such growth can affect local enterprises, which will suffer from the strong competition of these developments.
\end{abstract}

Keywords: Asian immigrants. Expansion of enterprises. Economic scenario

\footnotetext{
${ }^{1}$ Graduanda do Curso de Administração do Centro Universitário Doutor Leão Sampaio/Unileão, Juazeiro do Norte, Brasil. Contato: mluana19.a@gmail.com;

${ }^{2}$ Professora Mestre Orientadora, Centro Universitário Doutor Leão Sampaio/Unileão-email: tharsis @ leaosampaio.edu.br. 


\section{Introdução}

Devido as recentes mudanças econômicas, sociais e políticas diretamente envolvidas com a economia mundo e materializadas nos territórios nacionais, o processo de migração surge como algo extremamente complexo nesse contexto, por tal razão é destaque nos estudos sobre população trabalhados por diversas áreas do conhecimento científico. E por também considerar que o processo de movimentação de pessoas um espaço a outro, causa mudanças tanto nos territórios receptores como nos territórios emissores da migração. (BOMTEMPO; FERREIRA, 2016).

A região do Cariri, principalmente a cidade de Juazeiro do Norte, uma das maiores cidades do interior do Ceará, possui um grande "potencial de crescimento econômico e de desenvolvimento" (GAMA, 2014), tornando-a um polo atrativo para muitos empreendedores que enxergam uma oportunidade de abrir seu próprio negócio.

Diante desse cenário encontram-se os empreendimentos cujos donos são asiáticos, que pouco a pouco vão avançando na economia Juazeirense. Partindo desta explanação indaga-se o seguinte questionamento: Qual a percepção da população do centro da cidade em relação à expansão de empresas de origem asiática em Juazeiro do Norte?

Partindo desta explanação a pesquisa tem como objetivo compreender como a população enxerga à expansão de empresas de origem asiática na cidade de Juazeiro do Norte, analisando de acordo com suas percepções o que pode contribuir para o crescimento dessas empresas na região, como também identificar se a entrada das empresas comandadas por asiáticos pode ser positivo ou negativo apresentando assim o cenário de mercado da cidade de Juazeiro do Norte envolvendo os empreendimentos cujos proprietários são asiáticos

Nessa perspectiva a finalidade da pesquisa é analisar a expansão das empresas de origem asiática sob a ótica da população do centro da cidade de Juazeiro, a mesma servirá de embasamento para outras pesquisas que vierem a surgir relacionadas ao tema em estudo. A pesquisa traz em seu escopo um breve relato sobre os processos imigratórios asiáticos para o Brasil bem como as relações comerciais entre estes dois continentes. 


\section{Eixo Temático}

\section{Movimentos de Imigração dos Povos Asiáticos para o Brasil}

Data-se que após a abolição da escravatura em 1888, e com a crescente extração de café nas fazendas do estado de São Paulo, foi preciso buscar mão de obra externa para dar continuidade as colheitas cafeeiras. Foi neste período que se deu início o relacionamento entre o Brasil e o Japão com a chegada de migrantes para trabalharem nas lavouras de café. O sustentáculo para essa relação entre ambos foi a assinatura do tratado da amizade, comércio e navegação em novembro de 1895, e também pelo estabelecimento de companhias que faziam o processo de recrutamento e transporte de migrantes (OLIVEIRA, 2002).

Em 1908 é que se pode dizer que iniciou-se realmente a imigração japonesa para o Brasil, pois foi neste período em que o Japão precisava escoar boa parte de sua população e resolver os problemas internos da reforma política de Meiji por outro lado neste mesmo período o Brasil necessitava de mão de obra externa para trabalharem nas lavouras de café. Os imigrantes Japoneses se alocaram em diferentes regiões, principalmente no estado de São Paulo, norte do Paraná, Mato Grosso do Sul, Pará e Amazonas (SASAKI, 2006).

Seguindo os movimentos de imigração dos povos asiáticos para o Brasil, a imigração chinesa se deu a partir de meados dos anos de 1940 e 1950, intensificadas pela segunda Guerra mundial e da guerra civil na China. Por ser uma cultura totalmente diferente o processo de integração dos imigrantes chineses se deu de forma lenta. Esse processo imigratório pode ser divido em três etapas: o primeiro período foi do século XIX até a segunda guerra mundial, em que o fim da escravidão cada vez mais se tornando realidade, levou os donos das lavouras de a buscar mão de obra externa. O segundo foi período foi após a República popular da china ingressar na ONU, e um terceiro período datados anos 80 a 90 (JYE; SHYU, 2008).

Já a imigração coreana para o Brasil se deu no ano de 1963, segundo o Consulado Geral da República da Coreia em São Paulo, este sendo o principal destino da imigração coreana, estima-se que 50 mil pessoas tenham migrado para o país. O maior fluxo e datado nos anos 70 , tais coreanos desembarcaram no Brasil em busca de trabalho e do sonho de dias melhores se concentrando nas grandes metrópoles, principalmente em São Paulo. Passaram o tempo, muitos envelheceram mais ainda possuem dificuldades com o idioma. (HONG, 2013). 


\section{Relações Comerciais entre o Brasil e Países Asiáticos}

O Brasil possui interesses econômicos no continente asiático pela forte demanda por investimentos e acesso à tecnologia já a Ásia é um importante importador de produtos alimentícios e insumos básicos do Brasil, o que torna a parceria comercial entre ambos muito benéfica. Até a década de 70 o relacionamento entre o entre o Brasil e a Ásia limitava-se somente a relações econômicas com o Japão e relações de caráter político com a China, foi somente em meados dos anos 90 em que houve uma ampliação deste relacionamento com a entrada de novos parceiros comerciais (OLIVEIRA, 2002).

A partir da década de 90, houve uma retomada e ampliação do relacionamento entre o Brasil e Ásia, intensificando-se pela maior presença tanto da coreia do sul e dos países do sudeste asiático como também da China, que devido ao seu desenvolvimento acelerado, tornouse não só um ator político, mas um forte mercado consumidor e também fornecedor. (MASIERO; OLIVEIRA 2005).

\section{Relações Comerciais Brasil - China}

As relações comerciais entre o Brasil e a China se deram no ano de 1974, mas foi somente em 1978 em que houve intensificação maior desta relação entre ambos, pois foi neste período que ocorreu a assinatura do primeiro acordo comercial (PEREIRA, 2003).

Desde de 2009, a China tem sido o principal parceiro comercial do Brasil, durante esses anos vem se fortalecendo a troca comercial entre ambos tanto pelo comércio como também pelos investimentos realizados, em 2017 a china se mantém como um importante importador de produtos do Brasil sendo também o principal destino das exportações Brasileiras (FARIAS, 2018).

Segundo Oliveira e Santos (2014), o Brasil tem se tornado um grande exportador de alimentos e produtos intermediários à China, pela forte demanda chinesa por esses produtos, e o Brasil possui vantagem competitiva em tais produtos em relação a outros países asiáticos fornecedores. Por outro lado o Brasil tem adquirido mais produtos advindos da china como dispositivos eletrônicos. 
As importações e exportações entre esses dois países são benéficas para ambos, pois são partes importantes e constituintes de seu PIB, o que favorece a economia e o crescimento tanto do Brasil como da China, possibilitando o acesso a produtos que antes não eram acessíveis como por exemplo alguns aparelhos eletrônicos (DIAS; LEITE; MORI, 2016).

Entre os anos de 2007 e 2009, as trocas comerciais entre Brasil e a China se tornaram forte e intensas, com perspectivas de crescimento, mais ainda assim eram consideradas pouco relevantes. Em 2010 houve uma grande mudança, em que grandes empresas modificaram sua visão em relação ao Brasil, passando a enxergar um mercado promissor, anunciando grandes investimentos a serem feitos nos anos seguintes. "De 2010 a 2015, foi contabilizado um montante de investimentos de US\$ 67,5 bilhões em investimentos chineses anunciados no país, dos quais US\$ 37,1 foram confirmados". (FARIAS, 2018).

Segundo Ibidem entre 2014 e 2015, foi o momento de mudança nas relações sinobrasileiras não somente pelo volume de investimentos e comércio, mas também pela entrada dos chineses em outros setores de aspectos administrativos e estratégicos. O ano de 2015 as empresas chinesas efetuaram grandes operações de compra, e neste período o Brasil recebeu grandes investimentos de empresas chinesas. E mesmo com a atual instabilidade política e as eleições previstas para 2018, China deve continuar atendendo aos interesses econômicos e suas demandas, mantendo boas relações com o Brasil

\section{Relações Brasil - Japão}

As relações comerciais entre o Brasil e o Japão foram estabelecidas nos anos de 1960 e 1970, sendo marcadas pela forte intensificação dos investimentos e do comércio, o Brasil por um lado era um mercado promissor para os produtos industrializados advindos do Japão e por outro um dos principais fornecedores de matéria prima como minérios e alimentos ao Japão (CAVALCANTE, 2015).

Na década de 60 a relação entre esses dois países foi bastante fortalecida, o Japão se tornou um dos principais destinos das exportações brasileiras e fonte de investimentos no Brasil. Tal relação se fortaleceu pela iniciativa japonesa que em troca das matérias primas brasileiras, necessárias para o seu desenvolvimento, disponibilizava investimentos e produtos industrializados ao Brasil, já em 1970 houve o fortalecimento das relações políticas entre 
ambos, em que o Brasil intensificou seu interesse nas relações bilaterais, e em 1976 o então presidente Geisel realizou a primeira visita do Brasil deu um chefe do governo ao território japonês. (COSTA, 2010).

Os investimentos japoneses no Brasil que merecem destaque são os do setor automotivo, em atualmente estão associadas a associação de veículos automobilísticos (ANFAVEA): Honda, Komatsu, Mitsubishi Motors, Nissan, Toyota (NUNES, 2008).

\section{Relações Brasil- Coréia Do Sul}

Segundo o Ministério das relações exteriores (2018), As relações entre o Brasil e a república da Coreia (Coreia do Sul) foram estabelecidas no ano de 1959. O Brasil é o foi considerado o $8^{\circ}$ país do mundo e o um dos primeiros da América latina a reconhecer de maneira oficial a coreia do sul, a primeira embaixada brasileira foi estabelecida na capital coreana em 1965, já a embaixada sul-coreana foi instalada no Rio de janeiro em 1962, a primeira da América latina.

O Brasil e a Coreia do Sul são países com características similares no âmbito do desenvolvimento político e econômico ao longo do século XX, ambos foram comandados por militares nos anos 60 e 70 e possuem economias periféricas e industrialização tardia. O desenvolvimento destes dois países foi efetuado por dos planos nacionais de desenvolvimento, que visavam o incremento pesado da indústria, dessa forma buscavam substituir as importações e promover as exportações (COSTA, 2010).

Nos últimos anos, as relações entre o Brasil e a Coreia do Sul foi marcada pelo expressivo volume de investimentos coreanos no Brasil, em setores eletrônicos, siderúrgicos, automobilísticos e petrolíferos. No ano de 2014 o Brasil foi o $14^{\circ}$ destino das exportações sulcoreanas, já a coreia foi $23^{\circ}$ destino das importações brasileiras. (MINISTÉRIO DAS RELAÇOES EXTERIORES, 2018)

\section{Expansão dos Empreendimentos Asiáticos no Brasil e no Nordeste}

Nas últimas décadas Brasil vivenciou uma forte expansão a população de origem asiática, que pode ser justificada pelo retorno de brasileiros que residiam no Japão e pela 
imigração de chineses. Dados do censo de 2010 mostram que há no país 2.084 milhões de residentes que declaram de cor ou raça amarela, um aumento de 1.322 milhões de habitantes, em comparação com censo 2000. O autor ainda cita que há um novo desenho da distribuição dos asiáticos no Brasil, em que a região Nordeste passa ser um dos principais destinos, além do Sudeste e a grande São Paulo. A atração pelo nordeste pode se dá pelo aquecimento da economia na região, com investimentos em infraestrutura, serviços e aumento da mão de obra (LEAL, 2011).

Em Teresina, a população asiática não para de crescer e se pode encontrar vários comércios facilmente no centro da capital, negócios comandados por asiáticos mais encontrados são pastelarias e lojas de mercadorias importadas. (G1, 2014).

Para caracterizar o comercio chinês deve-se voltar ao processo imigratório dos asiáticos para o Brasil, em que a atividade comercial foi desenvolvida desde o início de sua chegada no país eram relacionadas a venda de bijuterias, bolsas, artigos de presentes como também voltadas para a gastronomia com as famosas pastelarias chinesas. (SOUSA, 2016)

No Ceará, os chineses migrantes estão localizados principalmente nos centros das cidades, em que há um maior fluxo de pessoas, e suas atividades estão voltadas para o comércio, são donos e também trabalhadores de lojas que comercializam produtos baratos, restaurantes e lanchonetes. A atuação e concentração desses imigrantes dinamizam a economia e a região cearense em múltiplas dimensões ao desenvolverem suas atividades laborais nos principais centros das cidades, nas principais ruas e galerias como visto em Fortaleza com as ruas Senador Pompeu, Barão do Rio Branco e General Sampaio, como também em Sobral com a Rua Viriato Medeiros e Juazeiro do Norte com a rua São Pedro, Principal rua em que se localizam os principais estabelecimentos comerciais. (BOMTEMPO; FERREIRA, 2016)

\section{Método}

A pesquisa em questão é de natureza básica, de abordagem quantitativa e trata-se de uma pesquisa de opinião desenvolvida com a população do centro da cidade de Juazeiro do Norte, para conhecer sua percepção em relação a expansão de empresas de origens asiáticas na região. Segundo Gil (2008), as pesquisas desse tipo são caracterizadas pela interrogação das pessoas, procurando obter informações de um determinado grupo a cerca de um problema 
estudado, por meio de uma análise quantitativa, obter conclusões correspondentes dos dados coletados.

Freitas e Prodanov (2013), destacam que a pesquisa de natureza básica tem como objetivo gerar novos conhecimentos que venham a ser utilizados nos avanços da ciência, não havendo uma aplicação prática imediata ou prevista. Afirmam ainda que quanto a abordagem quantitativa, têm como pressuposto que tudo pode ser quantificado, traduzindo números e opiniões em informações, classificando-as e analisando-as.

Para a obtenção da amostra foi delimitado um raio do centro da cidade de Juazeiro do norte que compõe a área onde há a maior concentração de empresas comandadas por asiáticos, para aplicação dos questionários, sendo delimitado da Rua são Pedro à Rua Santa Luzia, e a amostra foi calculada por acessibilidade. As pessoas inclusas nesta pesquisa são homens e mulheres na faixa etária de 18 aos 50 anos que residem no raio delimitado pelo pesquisador. Foram exclusos da pesquisa crianças e pessoas menores de 18 anos e acima de 50 anos.

Para coleta dos dados, foi elaborado e aplicado um questionário estruturado com 10 perguntas elaborado na plataforma do Google formulários acerca do tema pesquisado. As perguntas fechadas foram organizadas em gráficos gerados por essa ferramenta e em seguida feito sua devida analise. Já perguntas discursivas foram organizadas em corpus texto no bloco de notas para serem analisadas no software Iramuteq, por meio dele foi possível elaborar nuvem de palavras com as principais respostas repetidas e também gráfico de similitude. Ao total foram aplicados 75 questionários que formaram a amostra da pesquisa

A pesquisa possibilita mostrar como se encontra o mercado da cidade de Juazeiro do Norte, em relação a novos mercados entrantes, que seriam os empreendimentos dirigidos por asiáticos, proporcionando identificar qual a percepção das pessoas residentes no centro da cidade sobre a expansão dos empreendimentos de origem asiática na cidade de Juazeiro do Norte, como também servirá como embasamento para outras pesquisas que surgirem na área.

\section{Análise e Discussão dos Resultados}

A Pesquisa em questão foi realizada no centro da cidade de Juazeiro do Norte, em um raio de abrangência definido pelo pesquisador, sendo da rua São Pedro à rua Santa Luzia. Ao 
todo foram aplicados 75 questionários por meio de um formulário no Google para coletar os dados.

O questionário foi composto por 10 questões, sendo duas discursivas para os participantes exporem suas opiniões acerca da expansão dos empreendimentos de origem asiática e o que os levam a adquirir produtos ou serviços nesses empreendimentos ao invés de empreendimentos locais, como forma de compreender de acordo com suas percepções o que tem levado ao crescimento desses comércios no centro da cidade de Juazeiro do Norte.

A pesquisa foi realizada com uma amostra de 75 pessoas, em que os participantes da pesquisa de opinião a maioria encontram-se na faixa-etária de 18 a 26 anos, representando $73,3 \%$ do total, seguindo de 27 a 35 anos com o percentual de $21,3 \%$ e por fim os participantes da faixa-etária de 36 a 44 anos representaram 5,3\% do total.

A maioria dos respondentes são do sexo feminino com um percentual de $73,3 \%$ do total já o sexo masculino apresentou um percentual de $26,7 \%$. Nota-se a participação expressiva das mulheres na pesquisa sendo a maioria dos respondentes. $\mathrm{O}$ gráfico 01 aborda o conhecimento dos participantes acerca dos comércios existentes no centro da cidade de Juazeiro do Norte.

Gráfico 01- Conhecimento de empreendimentos de origem asiática

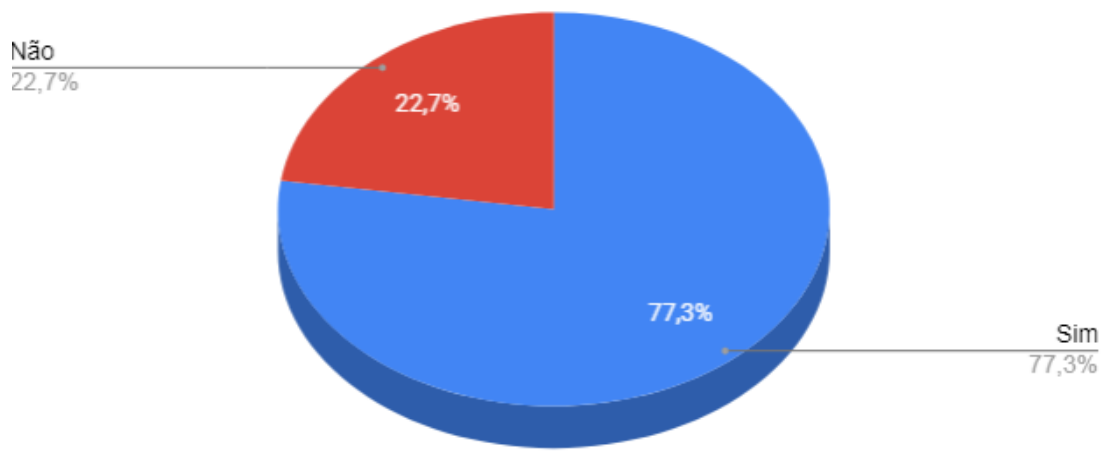

Fonte: Dados da pesquisa 2018

Observa-se por meio do gráfico que a maioria dos respondentes possuem conhecimento de algum empreendimento de origem asiática, sendo comércios ou prestadoras de serviços, o que mostra a perceptível expansão desses empreendimentos no centro da cidade. Apenas $22,7 \%$ ainda não possuem conhecimento de tais empreendimentos por ainda não terem frequentado.

O gráfico 02 aborda quais os tipos de empreendimentos de origem asiática hão em maior número no centro de Juazeiro do Norte-CE. 
Gráfico 02- Tipos de empreendimentos de origem asiática

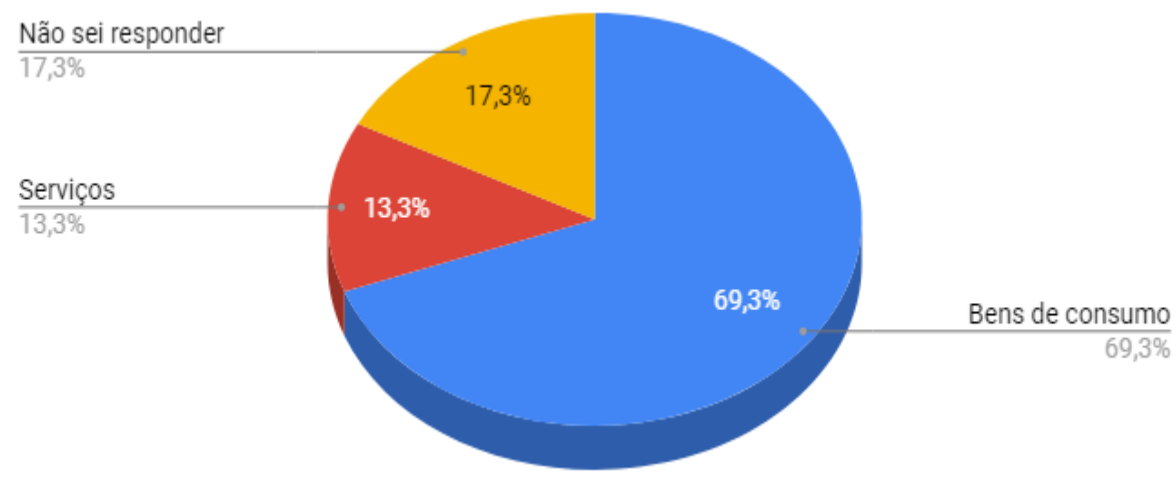

Fonte: Dados da pesquisa 2018

A partir da leitura do gráfico acima infere-se que a maioria dos entrevistados afirmam que há em maior número na cidade de Juazeiro do Norte empreendimentos de bens de consumo, outros $13,3 \%$ julgaram que há mais empreendimentos de prestação de serviços e outros 17,3\% não souberam responder.

Percebe-se assim que segundo a percepção dos participantes existem mais comércios no centro da cidade, como menciona que diz Bomtempo e Ferreira (2016) sobre no Ceará, em Juazeiro do norte os imigrantes chineses estarem localizados no centro da cidade e suas atividades estarem voltadas principalmente para o comércio. No gráfico 04 são apresentadas as principais compras dos participantes da pesquisa em empreendimentos de origem asiática.

Gráfico 04- Principais compras dos participantes

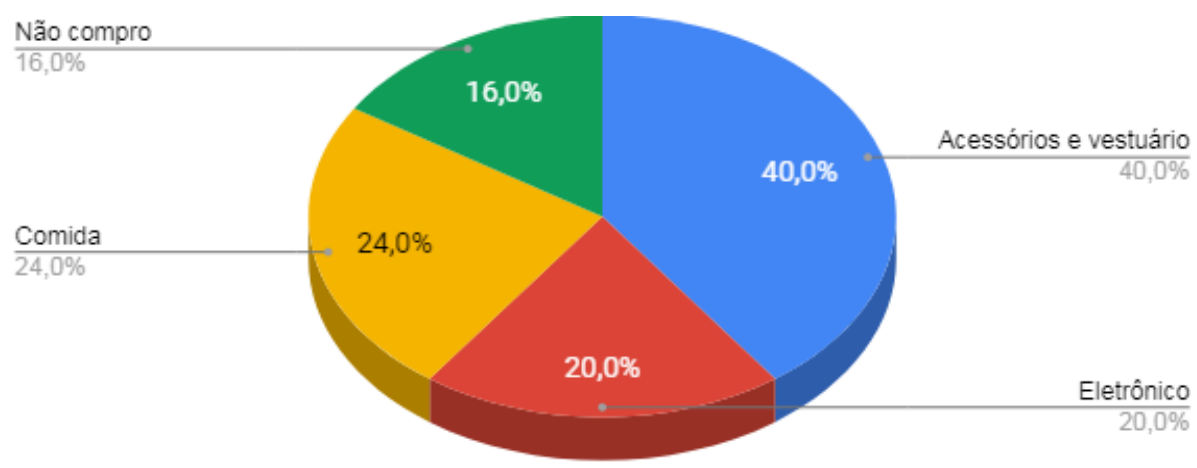

Fonte: Dados da pesquisa 2018 
Por meio do gráfico infere-se que dentre as principais compras das pessoas que frequentam empreendimentos de origem asiática, os acessórios e vestuários aparecem destacando-se como itens mais comprados pela maioria dos respondentes.

Em segundo lugar nas compras encontra-se o termo comida, ligada aos empreendimentos que desenvolvem atividades gastronômicas, como as pastelarias chinesas, em seguida vem os eletrônicos representando $20 \%$ das compras dos participantes, e outros $16 \%$ afirmaram não realizarem compras em empreendimentos de origem asiática.

Diante desse desenho de principais compras nota-se que os principais empreendimentos procurados no momento da compra são empreendimentos voltados para a venda de acessórios e vestuários seguida dos empreendimentos voltados para a gastronomia, o que vem a contribuir para a expansão desses empreendimentos na região. Sousa (2016) diz que as principais atividades comerciais desenvolvidas desde o início da chegada dos imigrantes asiáticos no país eram relacionadas a venda de bijuterias, bolsas, artigos de presentes como também voltadas para a gastronomia com as famosas pastelarias chinesas.

No gráfico 05 são apresentados de acordo com as percepções dos participantes o que tem levado ao crescimento de tantos empreendimentos cujos donos são asiáticos no centro da cidade de Juazeiro do Norte.

Gráfico 05- O que tem levado a expansão de empresas comandadas por asiáticos

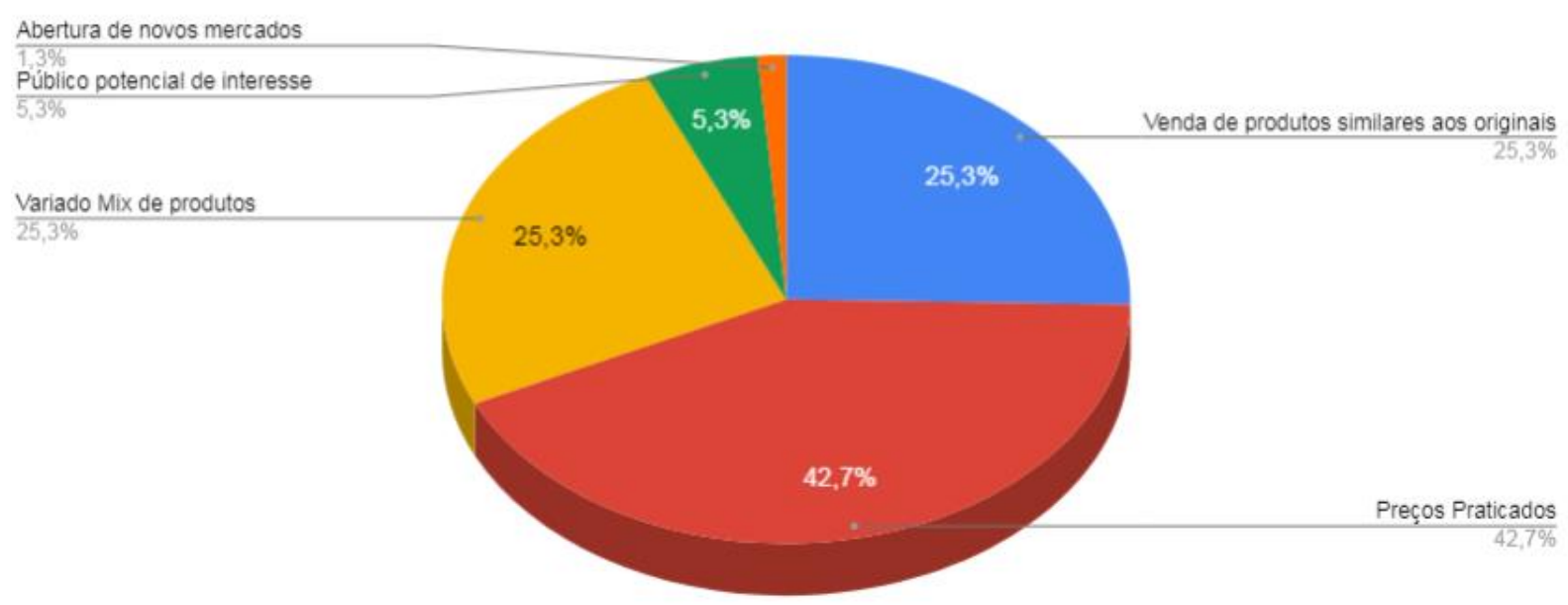

Fonte: Dados da pesquisa 2018 
De acordo com o gráfico 05 em que foi perguntado aos participantes de acordo com suas percepções quais motivos contribuíam para o crescimento de empreendimentos cujos donos são asiáticos no centro da cidade de Juazeiro do Norte, a maioria dos entrevistados afirmaram que os preços praticados são fatores principais para expansão desses empreendimentos visto que é um dos fatores principais na hora de escolha da compra.

25,3\% dos respondentes julgam eu o que tem contribuído para o crescimento desses empreendimentos são a venda de produtos similares aos originais, que são produtos réplicas dos originais mas que matem a qualidade.

Em seguida, também com o mesmo percentual aparece o variado mix de produtos ofertados, que segundo os entrevistados tem contribuindo para expansão dos empreendimentos, outros 5,35 \% julgam que tal expansão pode se dar devido ao público potencial de interesse, ou seja o aumento de pessoas interessadas em adquirir produtos ou serviço desses empreendimentos contribuindo para o seu crescimento na cidade.

E por fim 1,3\% afirmaram que abertura de novos mercados. Infere-se com isso que boa parte dos entrevistados julga que a expansão desses empreendimentos está atrelada principalmente aos preços praticados e a variedade similaridade dos produtos com os originais. No gráfico 06 são apresentadas as percepções dos participantes quanto a avaliação da expansão desses empreendimentos citados anteriormente no mercado da cidade.

Gráfico 06- Avaliação da expansão dos empreendimentos no mercado da cidade

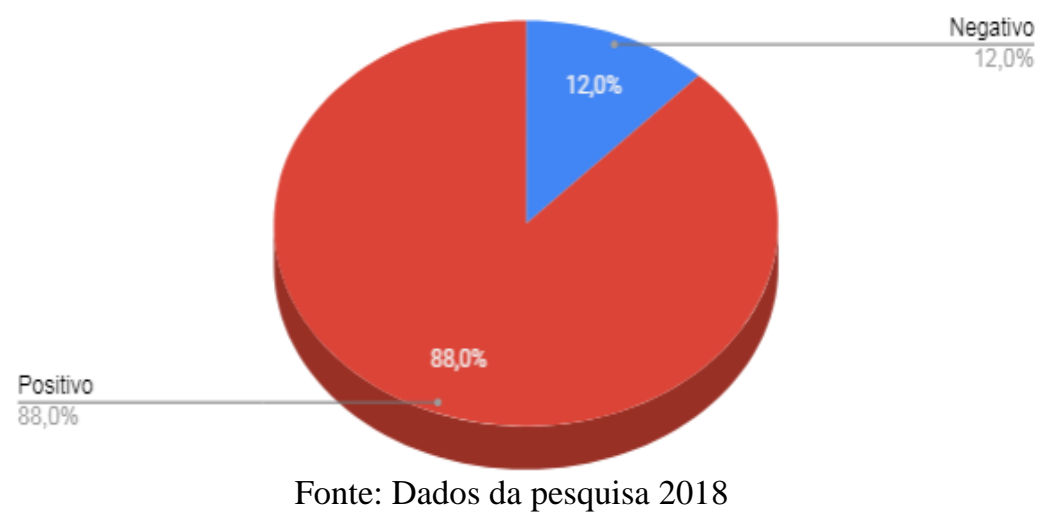

Observa-se com o gráfico 06 que a maioria dos respondentes julgam a expansão dos empreendimentos comandados por asiáticos como positivo para o mercado da cidade, cerca de $88 \%$ afirmaram que o crescimento pode sim ser benéfico para o mercado de Juazeiro do norte 
podendo as pessoas terem mais oportunidades de escolhas na hora da compra. Quanto que $12 \%$ afirmam que tal expansão é negativa para o comércio da cidade isso por que a expansão pode afetar de alguma forma os empreendimentos locais.

Foram também abordadas perguntas discursivas no questionário aplicado, como forma de buscar compreender melhor a opinião dos participantes sobre a expansão dos empreendimentos asiáticos no centro da cidade. Foi questionado aos participantes sobre o que os faziam adquirir produtos ou serviços em empreendimentos cujos donos são asiáticos ao invés de empreendimentos locais.

Figura 01: O que os fazem adquirir produtos ou serviços de empreendimentos comandados por asiáticos

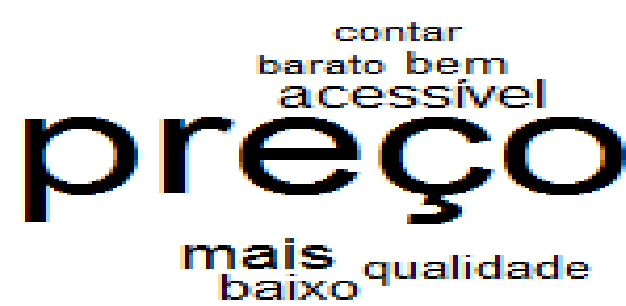

Fonte: Dados do Iramuteq

Por meio do software Iramuteq foi possível analisar as respostas do questionamento acima criando uma nuvem de palavras, cujas palavras são as que mais se repetiram nas respostas dos participantes. De acordo com imagem o principal elemento que motiva os participantes ao adquirir um produto ou serviço de empreendimentos comandados por asiáticos é o preço e diretamente ligado a este termo podemos ver "mais baixo", "bem acessível", "barato" reforçando a ideia de que as pessoas que frequentam tais empreendimentos levam como fator principal o preço na hora de decisão da compra. Ainda podemos observar o termo qualidade que também foi um dos termos mais repetidos nas respostas, mostrando que a qualidade dos produtos e serviços também é um elemento chave que os fazem adquirir em empreendimentos de origem asiática ao invés de empreendimentos locais. Em uma outra perguntar discursiva procurou-se compreender como os participantes enxergam o crescimento de empresas de donos asiáticos na cidade de Juazeiro do Norte-CE. 
Gráfico 07: Percepção dos participantes sobre o crescimento de empresas de origem asiáticas

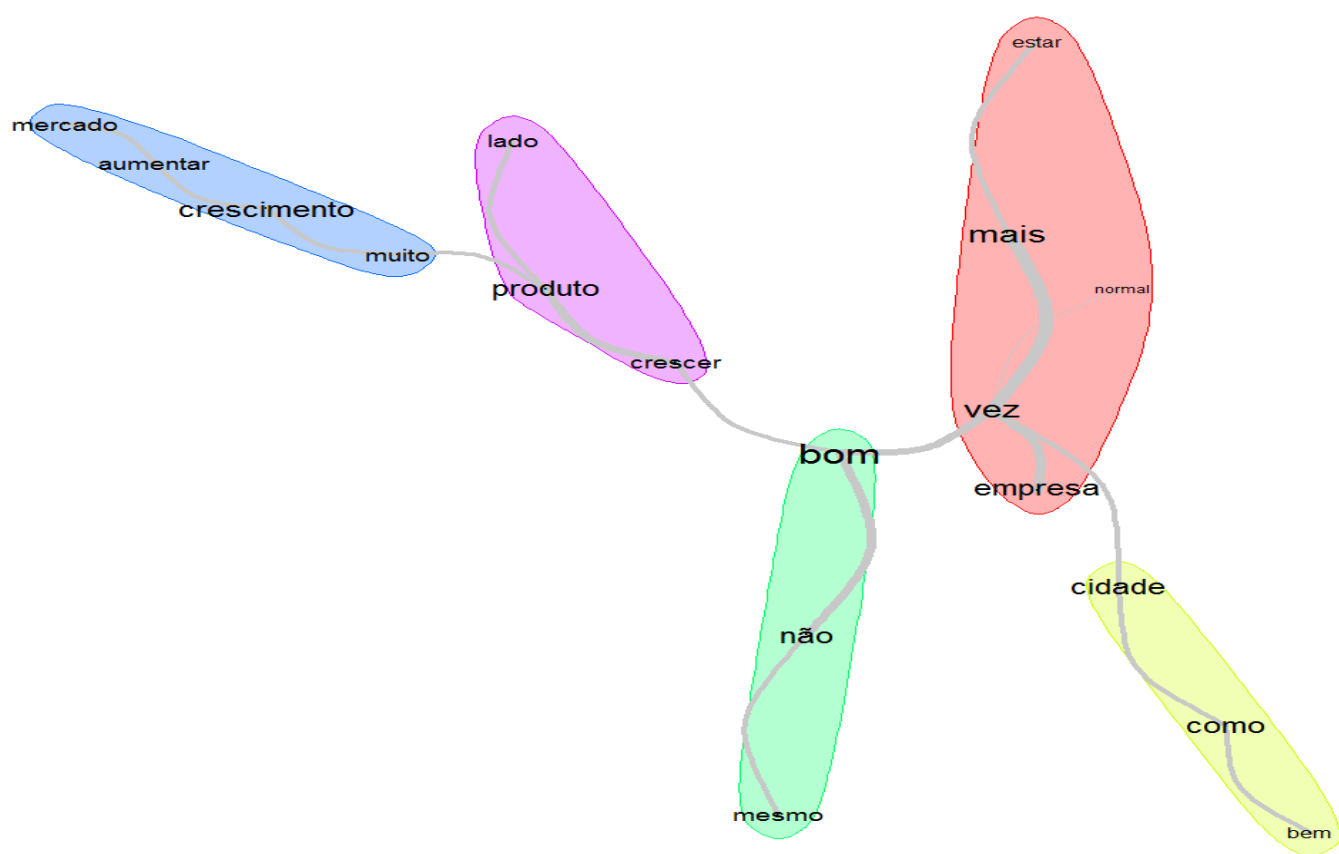

Fonte: Dados do Iramuteq

De acordo com o gráfico de similitude gerado pelo Iramuteq em que é possível de acordo com as respostas dos participantes, termos repetidos serem ligados a outros formando uma espécie de ligação de raízes, em que se pode observar na região azul os termos "mercado", "aumentar, "crescimento" e "muito" o que infere-se que na percepção dos participantes os empreendimentos cujos donos são asiáticos estão avançando no mercado da cidade e seu crescimento e sua expansão é notório no centro da cidade de Juazeiro do Norte. .

Na região roxa do gráfico observa-se os termos "Produto", "crescer", "lado" mencionado por muitos dos entrevistados que responderam que o aumento da circulação produtos e do mix ofertado, por um lado é o que tem contribuído bastante para a expansão desses empreendimentos na cidade.

Já na região rosa do gráfico nota-se os termos "estar", "mais", "normal", "vez "e "empresa" sinaliza o que boa dos entrevistados responderam sobre ser cada vez mais ser normal encontrarmos empresas de origem asiáticas no centro da cidade. Ainda com o auxílio do 
software Iramuteq foi gerado uma nuvem de palavras de acordo com as respostas dos entrevistados.

Figura 02: Percepção dos participantes sobre o crescimento de empresas de origem asiáticas

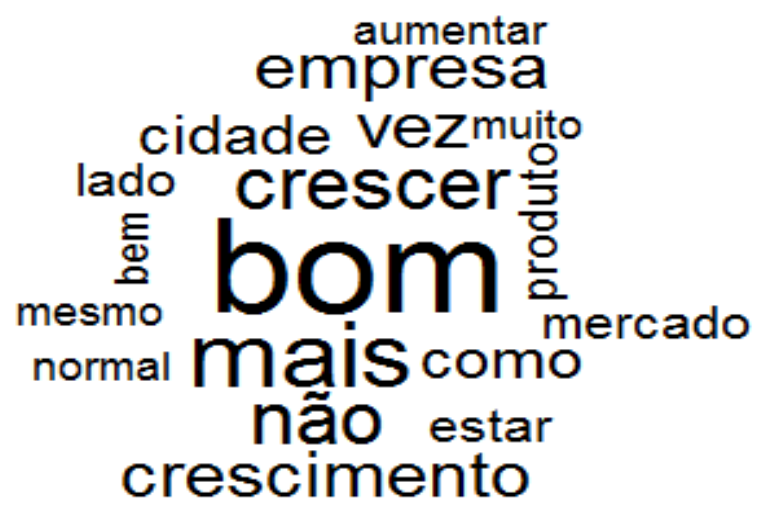

Fonte: Dados do Iramuteq

Por meio da figura observa-se que uma boa parcela dos respondentes julga como "bom" o crescimento desses empreendimentos no mercado da cidade. Também houveram respostas negativas quanto o crescimento dos mesmos no mercado da cidade sendo percebido pelo termo "não", na área verde do gráfico de similitude e na figura 02, sinalizando o que muitos afirmaram que a expansão pode ser negativa no sentido de que isso pode afetar os empreendimentos locais.

Podendo ser percebidos nas falas de alguns dos entrevistados como: "Tem seu lado bom e ruim, o bom é que gera emprego mesmo sendo de carteira assinada ou não. O ruim é que são concorrentes para os comerciantes da Cidade de Juazeiro do Norte". Outro ainda menciona "Prejudicial para aqueles que vendem os produtos originais e incorre tributos que os mesmos não pagam por entrarem ilegal no Brasil". Conduto muitos julgam que é um mercado que cada vez mais estar crescendo na região, e se torna benéfico para a população pois assim terá mais oportunidades de escolhas e disponibilidade de produtos e mix variados.

\section{Considerações Finais}

A cidade de Juazeiro do Norte-Ce é um dos grandes polos de crescimento e de desenvolvimento econômico, atraindo uma atenção especial de muitos empreendedores que enxergam nessa região a oportunidade de empreender e possuir seu próprio negócio.

461 Id on Line Rev. Mult. Psic. V.12, N. 42, Supl. 1, p. 447-464, 2018 - ISSN 1981-1179 Edição eletrônica em http://idonline.emnuvens.com.br/id 
Nessa perspectiva percebe-se o aumento do fluxo de imigração de asiáticos no centro da cidade, todos movidos pela oportunidade de mudar de vida e poder ser dono do seu próprio negócio. É notório o aumento do número de empreendimentos de origem asiática no centro de Juazeiro do Norte, e sua expansão pode estar atrelada a diversos fatores, afetando diretamente o mercado ao qual está inserido.

Com isso a pesquisa procurou compreender qual a percepção da população do centro da cidade sobre a expansão dos empreendimentos de origem asiática, questionamento esse que foi respondido satisfatoriamente ao longo da pesquisa ao perceber que de acordo com a percepção dos entrevistados esses empreendimentos estarem avançando e crescendo cada vez mais na economia da cidade e isto pode estar diretamente ligado a forma de atuação dessas empresas, ofertando produtos similares aos originais a preços baixos, mas mantendo a qualidade.

Por mais que a expansão dos empreendimentos de origem asiática seja benéfica para a população do centro da cidade de Juazeiro do norte- CE, pois possibilita mais oportunidades de escolha na hora da compra e variados mix, tal crescimento pode afetar os empreendimentos locais, que irão sofrer com a forte concorrência desses empreendimentos, já que é um mercado, que de acordo com a percepção dos mesmos, está em forte crescimento.

Os objetivos propostos nessa pesquisa foram alcançados satisfatoriamente na medida em que tornou-se possível compreender a percepção dos entrevistados em relação a expansão dos empreendimentos asiáticos, em que a maioria julgou como algo positivo para cidade. $\mathrm{E}$ sobre o que motiva tal expansão também ficou claro que a questão dos preços praticados e o mix de produtos foram fatores muito citados ao longo da pesquisa como fatores que impulsionam o crescimento e a expansão dos empreendimentos de origem asiática.

\section{Referências}

BOMTEMPO, Denise Cristina; FERREIRA, Elidiane Silva. A china que ninguém vê: migrantes chineses no centro comercial das cidades cearenses. Disponível em:< http://periodicos.uem.br/ojs/index.php/BolGeogr/article/view/33906>. Acesso em: 22 set 2018.

BUSTELO, Santiago; CARIELLO, Tulio; FRAGOSO, Gabriel. Investimentos Chineses no Brasil 2016. Disponível em:< www.cebc.org.br/sites/default/files /investimentoschinesesnobrasil2016_pt.pdf,>. Acesso em: 05 maio 2018. 
CAVALCANTE, Tamirys Ferreira. As relações nipo-brasileiras: perspectivas da cooperação em interesses complementares. Disponível em:< http://www.funag.gov.br /ipri/btd/index.php/10-dissertacoes/4608-as-relacoes-nipo-brasileiras-perspectivas-dacooperacao-em-interesses-complementares>. Acesso em: 01 jul 2018.

COSTA, Juliana. Brasil e Coréia: uma relação em construção. Disponível em:< https://liceu.emnuvens.com.br/LICEU_ON-LINE/article/viewFile/865/675> Acesso em: 01 jul. 2018.

DIAS, Carina Roberta; LEITE, Gislaine de Souza; MORI, Juliana Sampaio. Evolução das relações comerciais entre Brasil e China: Uma análise dos anos 2002 a 2014. Disponível $\mathrm{em}:<$ http://www.revistaespacios.com/a16v37n24/16372416.html $>$. Acesso em: 25 mar. 2018

FARIAS, Anna Carolina Monéia. O que considerar para as relações comerciais BrasilChina em 2018?. Disponível em:< http://www.chinalinktrading.com/blog/relacoescomerciais-brasil-china-2018/>. Acesso em: 20 mar. 2018.

FREITAS, Ernani Cesar de; PRODANOV, Cleber Cristiano. Metodologia do trabalho científico: métodos e técnicas da pesquisa e do trabalho acadêmico. - 2. ed. - Novo Hamburgo: Feevale, 2013.

G1.GLOBO. Cresce número de pontos comerciais comandados por chineses no Piauí. Disponível em: < http://g1.globo.com/pi/piaui/noticia/2013/08/cresce-numero-de-pontoscomerciais-comandados-por-chineses-no-piaui.html> Acesso em: 20 jul. 2018.

GAMA, Déborah. Crescimento econômico de Juazeiro do Norte / CE. Disponível em: < http://deborahcorretora.com.br/tag/crescimento-economico-de-juazeiro-do-norte/>. Acesso em: 15 mar. 2018.

GIL, Antonio Carlos. Métodos e técnicas de pesquisa social. - 6. ed. - São Paulo: Atlas, 2008.

JYE, Chen Tsung; SHYU, David Jye Yuan. Integração cultural dos imigrantes chineses no Brasil. Disponível em: < https://www.revistas.usp.br/reo/article/view/90748,>. Acesso em: 05 maio 2018.

LEAL, Luciana Nunes. Censo 2010: população asiática no Brasil cresceu 177\% em dez anos. Disponível em:< https://brasil.estadao.com.br/noticias/geral,censo-2010-populacao-asiaticano-brasil-cresceu-177-em-dez-anos,748616> Acesso em: 22 set. 2018.

MASIERO, Gilmar; OLIVEIRA, Henrique Altemani de. Estudos Asiáticos no Brasil: contexto e desafios. Disponível em: $<$ www.scielo.br/pdf/rbpi/v48n2/a01v48n2.pd $>$. Acesso em 23 mar. 2018.

MINISTÉRIO DAS RELAÇÕES EXTERIORES. Republica da Coreia. Disponível em:< http://www.itamaraty.gov.br/pt-BR/ficha-pais/5051-republica-da-coreia>. Acesso em: 20 jun 2018. 
NUNES, Paulo Henrique Faria. As relações brasil-japão e seus reflexos no processo de ocupação do território brasileiro. Disponível em:< http://www.uel.br/revistas/uel/index.php/geografia/article/viewFile/2618/2281>. Acesso em: 20 jun. 2018.

OLIVEIRA, Henrique Altemani de. Os blocos asiáticos e o relacionamento brasil-ásia. Disponível em: $<\quad$ http://www.scielo.br/scielo.php?script=sci_arttext\&pid=S010288392002000100012>. Acesso em: 24 mar. 2018

OLIVEIRA, Marianne Costa; SANTOS, Débora Almeida Nascimento dos. Relação econômica entre Brasil e china no período de 2008 a 2013. Disponível em:< http://www.uesc.br/eventos/ivsemeconomista/anais/gt3-2.pdf>. Acesso em: 19 mar. 2018.

PEREIRA, Ronan Alves. Estudos Asiáticos no Brasil. Disponível em: < www.repositorio.unb.br/bitstream/10482/1591/.../CAPITULO_EstudosAsiaticosBrasil.pdf >. Acesso em: 25 mar. 2018.

SASAKI, Elisa. A imigração para o Japão. Disponível em: <www.scielo.br/pdf/ea/v20n57/a09v2057.pdf>. Acesso em: 23 Abr. 2018 > Acesso em: 28 abr. 2018

SOUSA, Gerson dias de. Um negócio da china: A Dinâmica do Comércio no Centro de Teresina a Partir da Presença dos Chineses. Disponível em:< http://www.eng2016.agb.org.br/resources/anais/>

Como citar este artigo (Formato ABNT):

MELO, Maria Luana de; ALENCAR, Tharsis Cidália de Sá Barreto Diaz . Percepção da População do Centro da Cidade de Juazeiro do Norte sobre a Expansão dos Empreendimentos de Origem Asiática. Id on Line Rev.Mult. Psic., 2018, vol.12, n.42, Supl. 1, p. 447-464. ISSN: 1981-1179.

Recebido: 08/11/2018;

Aceito: 09/11/2018 